\title{
Modified Le Fort I Osteotomy and Genioplasty for Management of Severe Dentofacial Deformity in $\beta$-Thalassaemia Major Case report and review of the literature
}

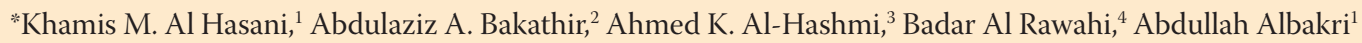

$$
\begin{aligned}
& \text { تعديل في القطع العظمي لوفور } 1 \text { ورأب الذقن لعلاج تشوه سني وجهي حاد } \\
& \text { لحالة مصابة بأنيميا البحر المتوسط البور الكبرى } \\
& \text { تقرير حالة مع مراجعة أدبية }
\end{aligned}
$$

$$
\text { خميس محمد الحسني، عبدالعزيز عبداله باكثير، أحمد خميس الهاشمي، بدر الرواحي، عبداله البكري }
$$

ABSTRACT: $\beta$-thalassaemia major is an autosomal recessive form of haemoglobinopathy that is characterised by complete lack of production of the $\beta$-chains resulting in multiple complications that include severe anaemia, failure to thrive and skeletal abnormalities. Facial deformities induced by $\beta$-thalassaemia major are rare and are very challenging to treat from a surgical point of view. We report a 33-year-old female patient with $\beta$-thalassaemia major who presented to the Dental \& Maxillofacial Surgery Department, Sultan Qaboos University Hospital, Muscat, Oman, in 2017 with gross dentofacial skeletal deformity contributing to her psychosocial issues. The facial deformity was corrected surgically by excision of the enlarged maxilla, modified Le Fort I osteotomy and advancement genioplasty. This case highlights the pre-operative preparation, surgical management, encountered complications and treatment outcome within 24 months of follow-up.

Keywords: Beta-Thalassaemia; Thalassaemia Major; Cooley's Anemia; Le Fort Osteotomy; Genioplasty; Dentofacial Deformities; Case Report; Oman.

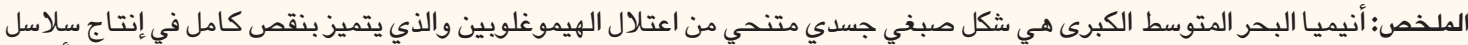

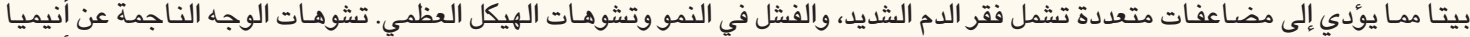

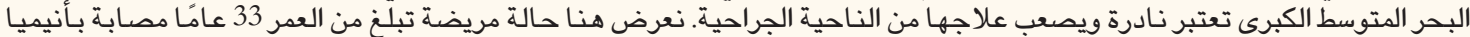

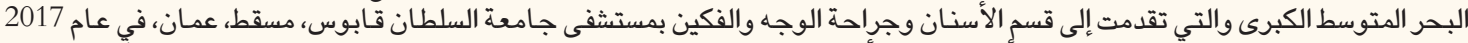

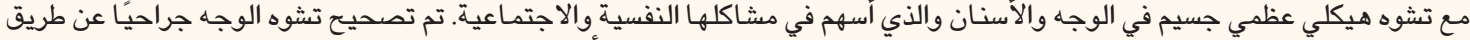

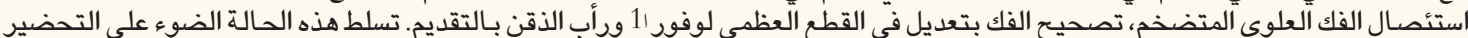
قبل الجراحة والإدارة الجراحية والمضاعفات التي تم مواجهتها ونتائج العلاج خلاج خلال فترة 24 شهرًا من المتابعة.

الكلمات المفتاحية؛ أنيميا البحر المتوسط الكبرى ؛ فقر الدم كولي؛ قطع عظم لوفور؛ رأب الذقن؛ تشوهـات الأسنان والوجه؛ تقرير حالة؛ عُمان.

$\beta$ -THAlassaemia has BeEn RePORTED AS THE most common autosomal recessive mutational disorder of haemoglobin ( $\mathrm{Hb}$ ) synthesis, which is characterised by reduction or absent synthesis of the $\beta$-globin chains of the Hb tetramer. ${ }^{1}$ Cooley and Lee reported the first thalassaemia case in 1925 presenting with severe anaemia, splenomegaly and characteristic skeletal abnormalities., ${ }^{1,2}$

$\beta$-thalassaemia is classified according to the mutation in the $\beta$-globin genes as thalassaemia minor, intermedia and major subtypes. ${ }^{3}$ Clinically, $\beta$-thalassaemia major patients present with chronic severe anaemia, failure to thrive, hepatosplenomegaly, myocardial diseases, skeletal abnormalities and other complications $^{4-7}$

Skeletal changes are common features in $\beta$-thalassaemia major patients, and in the craniofacial region these include bossing of the skull, prominent malar eminences giving the typical mongoloid facial appearance and maxillary hypertrophy. ${ }^{1,2,5,6}$ As a consequence of inadequate erythropoiesis, hypertrophy of erythroid marrow tissue especially at medullary sites lead to the typical craniofacial deformities that are usually seen in poorly transfused individuals. ${ }^{3,6,7}$ 


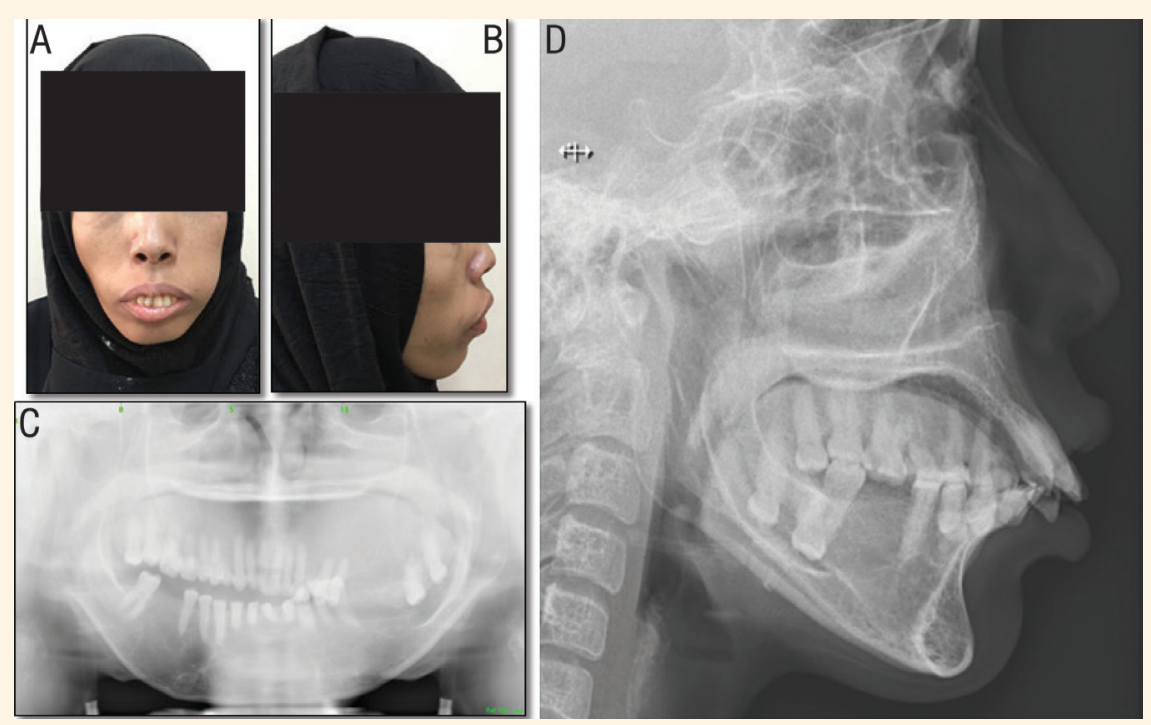

Figure 1: Pre-operative clinical photographs and radiographic images of a 33-year-old female patient with $\beta$-thalassaemia showing (A) frontal and (B) lateral views showing lip incompetence, excessive teeth showing and maxillary enlargement. Orthopantogram showing $(C)$ left maxillary enlargement with obliteration of the maxillary sinuses and over-eruption of left maxillary teeth. Lateral cephalogram showing (D) severe proclination of the upper and lower anterior teeth, increased overjet and moderate retrogenia.

Surgical management of the facial deformity in $\beta$-thalassaemia major patients is challenging. Various surgical treatment options have been advocated particularly for the surgical correction of the enlarged maxilla, however, most are published as case reports with some controversies on the complexity of these procedures. ${ }^{8-10}$

We report a rare case of severe dentofacial deformity in a $\beta$-thalassemia major patient who underwent surgical correction with a successful and stable outcome.

\section{Case Report}

A 33-year-old female patient with $\beta$-thalassaemia major was referred to the Dental \& Maxillofacial Surgery Department, Sultan Qaboos University Hospital, Muscat, Oman, in 2017 for evaluation and management of her dentofacial deformity. The patient's chief complaints were related to her poor aesthetics, malocclusion and excessive upper jaw enlargement.

The patient was diagnosed with $\beta$-thalassaemia major at the age of two years and was also known to have diabetes mellitus, coagulopathy and moderate liver iron over-load. Moreover, she had no history of splenectomy or platelet dysfunction and her medical treatment included regular monthly blood transfusions, metformin and oral iron-chelating agents, which were recently changed to intravenous deferoxamine to improve her iron over-load status.

Clinical examination showed pallor of the skin and oral mucosa, prominent left maxilla, incompetent lips with excessive tooth show at rest. Intraorally, there was an excessive vertical expansion of the left maxilla resulting in an occlusal cant. There was also malocclusion with dental crowding and a noticeable increased overjet [Figure 1].

Radiographic imaging showed poor maxillary bone density with obliteration of the maxillary sinuses and gross left maxillary bone enlargement especially in the premolar and molar regions [Figures 1 and 2]. A lateral cephalogram showed severe proclination of the upper and lower anterior teeth and moderate retrogenia.

The patient requested surgical correction of her dentofacial deformity. Surgical options including conventional orthodontic-orthognathic treatment, modified Le Fort I osteotomy and genioplasty with excision of the enlarged maxillary mass were explained to the patient. The patient understood the due risks and complications. She chose the modified maxillary osteotomy and genioplasty without pre-surgical orthodontics.

The patient's pre-operative investigations showed a haemoglobin level of $9 \mathrm{~g} / \mathrm{dL}$, deranged coagulation with increased activated partial thromboplastin time and fibrinogen as well as reduction factor IX and XII levels. Pre-operatively, a haematologist was consulted and the recommended blood transfusion raised the patient's $\mathrm{Hb}$ level to $11.4 \mathrm{~g} / \mathrm{dL}$ and transfused fresh frozen plasma (FFP) was arranged to correct the coagulopathy status.

Under nasotracheal intubation and antibiotic prophylaxis with second-generation cephalosporin, 

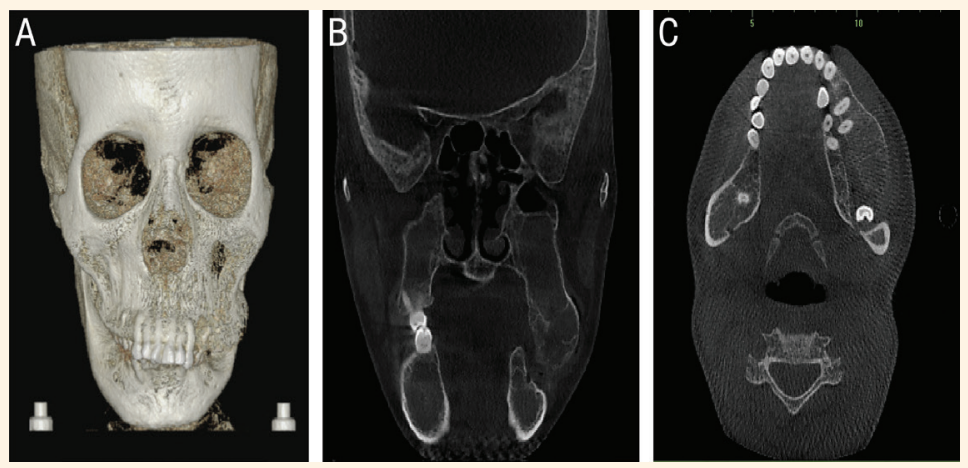

Figure 2: Pre-operative cone beam computed tomography of the head of a 33-year-old female patient with $\beta$-thalassaemia showing (A) 3-dimensional reconstruction scan showing extensive left maxillary mass with lack of bony cortex. Coronal (B) and axial (C) cuts demonstrating left maxillary medullary expansion with overlapping downward overgrowth of the left maxilla and obliteration of the maxillary sinuses.

bilateral full crevicular incisions were performed to expose the maxilla, which revealed a lack of bony cortex with presence of very loose honeycombed medullary bone overlying the expanded maxilla. The hypertrophied bone of the left maxilla was excised together with extractions of maxillary posterior teeth 18, 17, 27 and 28. At the extraction sites, bilateral vertical osteotomies were performed which were linked by bilateral horizontal osteotomies $5 \mathrm{~mm}$ above the apices of the remaining teeth (modified Le Fort I osteotomy without involving the pterygoid plates or the nasal floor). An additional horizontal osteotomy was performed above the initial horizontal osteotomy bilaterally to facilitate maxillary impaction, by removing a wedge of bone between the two horizontal osteotomies. The maxilla, as a single segmental unit, was then mobilised and impacted $6 \mathrm{~mm}$ on the right side and $4 \mathrm{~mm}$ on the left side and was set back by $4 \mathrm{~mm}$. Fixation was then accomplished using five $2.0 \mathrm{~mm}$ bone plates and screws with good stability. Following the closure of the maxillary surgical area, a conventional $6 \mathrm{~mm}$ advancement genioplasty was performed uneventfully [Figure 3].

Intra-operatively, persistent oozing from the hyperplastic maxilla was encountered throughout the procedure, which resulted in dropping of the $\mathrm{Hb}$ level to $7 \mathrm{~g} / \mathrm{dL}$, requiring multiple blood and FFP transfusions. The combination of using absorbable haemostatic agent (Surgicel ${ }^{\circledR}$, Ethicon, Hamburg, Germany) packing, tranexamic acid, stable maxillary fixation and soft tissue closure resulted in good control of the intra-operative bleeding.

Post-operatively, the patient developed moderate facial oedema, mild maxillary oozing but had no signs of surgical infection. Local measures consisting of oral packing and tranexamic acid rinses were utilised to control the post-operative ooze. Further postoperative drop of $\mathrm{Hb}$ required an additional two units of blood transfusion.

Two weeks post-operatively, the patient's general condition improved with resolution of the facial oedema and adequate healing of the surgical sites with satisfactory occlusion, acceptable tooth show at rest and a good facial profile. At 24 months follow-up, the patient was pleased with the surgical outcome and clinical assessment revealed satisfactory facial profile and stable occlusion with no evidence of significant surgical relapse [Figure 4].

The patient's verbal consent was obtained to use her clinical images for educational and publication purposes; this was documented in the patient's medical file.
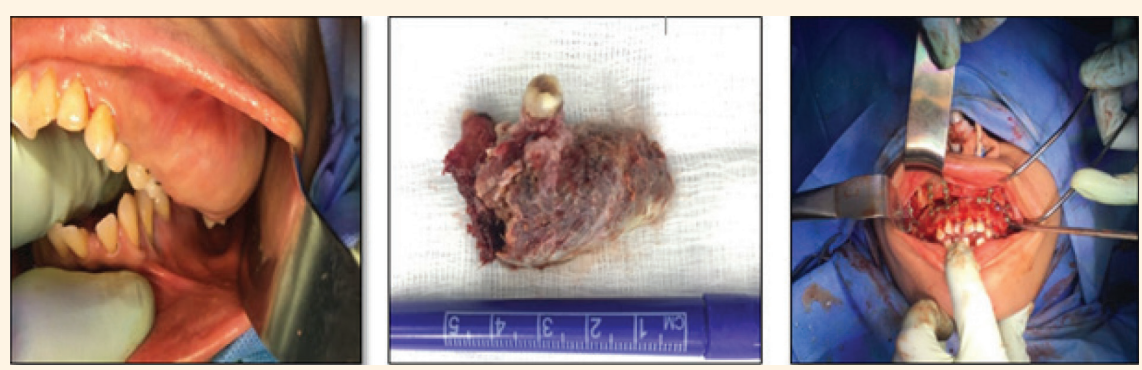

Figure 3: Intra-operative surgical photographs of a 33-year-old female patient with $\beta$-thalassaemia showing the intraoral view showing a hypertrophied left maxillary bony mass, excised hypertrophied left maxillary mass and fixation and stabilisation of modified Le Fort osteotomy with multiple mini-plates. 

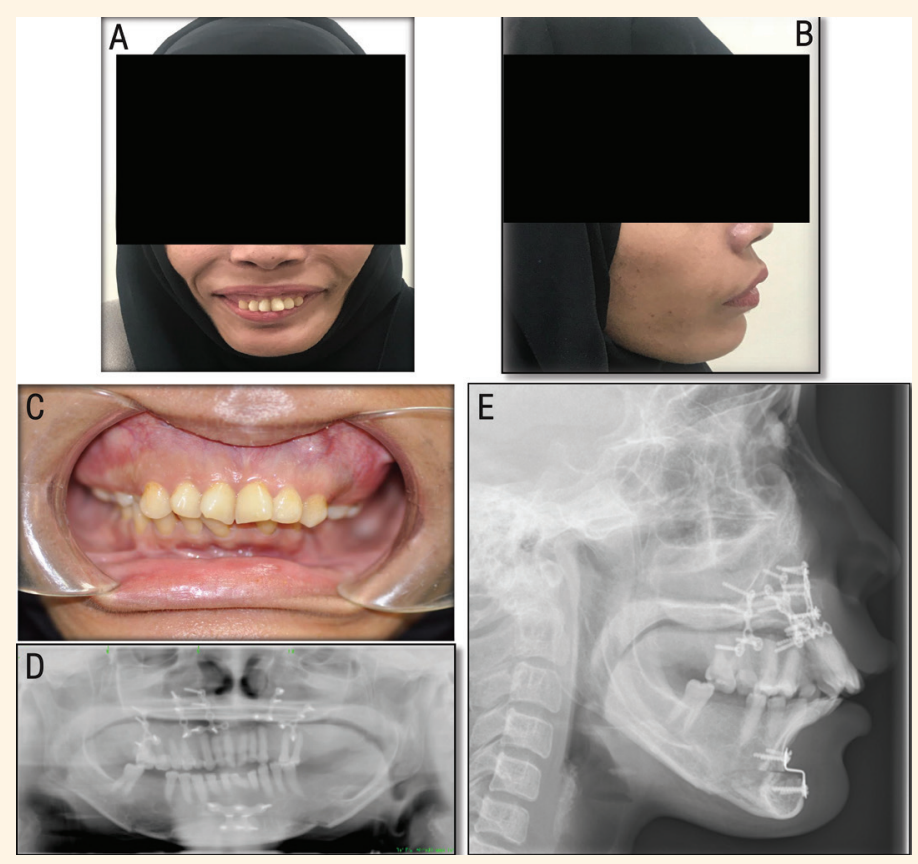

Figure 4: Post-operative (24 months) clinical photographs and radiographic images of a 33-year-old female patient with $\beta$-thalassaemia showing the (A) frontal and (B) lateral views showing a pleased patient with satisfactory facial profile. Intra-oral view showing $(\mathbf{C})$ stable occlusion with symmetrical and harmonised maxillary buccal buttress. Orthopantogram showing (D) stable occlusion with plates used for mandibular and maxillary osteotomy procedure and (E) a lateral cephalogram showing satisfactory chin position and lateral profile.

\section{Discussion}

$\beta$-thalassaemia major, also known as Cooley's anaemia and transfusion-dependent thalassaemia, is a hereditary form of severe anaemia that is commonly prevalent among natives of the Mediterranean and Middle Eastern and Asian countries. ${ }^{3}$ In recent years, the life expectancy of $\beta$-thalassaemia major patients has improved dramatically as reported in different countries, nevertheless, serious disease-related complications are still common and pose a direct impact on the quality of life and increases patient morbidity and mortality. ${ }^{11-13}$

$\beta$-thalassaemia major patients are well known to have skeletal changes, particularly orofacial deformity and the prevalence and severity of such deformity coincides with the degree of ineffective erythropoiesis and extra-medullary haematopoiesis. ${ }^{6,14}$ The typical features of the facial deformity manifest clinically as frontal bossing, obliteration of the nasal sinuses, depression of the nasal bridge, protrusion of zygoma and expansion of the maxilla giving rise to a chipmunk-like appearance or rodent-like face and dental malocclusion. ${ }^{14}$ The pathogenesis of such skeletal changes are related to the hyperplasia and hypertrophy of the marrow erythroid under influence of the hyperactivity of the red marrow that leads to expansion of the medullary cavities and thinning of the cortical structures resulting in an overall loss of bone density, which is commonly seen in the maxilla. ${ }^{6,14,15}$ The facial changes are more pronounced as haematopoiesis continues in the cranium compared to other sites in the body. The mandible undergoes less changes than the maxilla and usually

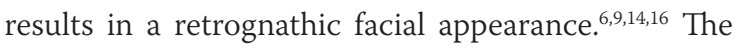
dentition appears displaced as a consequence of the maxillary expansion and accordingly, results in dental malocclusion and functional difficulties during eating, swallowing and speech. ${ }^{9}$

Iron over-load is a common complication in $\beta$-thalassaemia major patients. ${ }^{1,3,10,17,18}$ It occurs due to the ineffective erythropoiesis and/or transfusion iron over-load. Ineffective erythropoiesis promotes an increase of the intestinal iron uptake that has an influence over iron balance regulation. In addition, iron also has the potential to precipitate within the parenchyma of the heart and liver and eventually leads to haemochromatosis. Growth impairment, cirrhosis, hepatosplenomegaly, endocrine and metabolic abnormalities and cardiac complications are the main sequelae of haemochromatosis.,10,13,17-19 Oral iron chelating agents are widely used in $\beta$-thalassaemia major patients to prevent iron over-load. ${ }^{1,3,10,17,18}$ Evidence suggests that iron chelation therapy can arrest the progression of endocrine abnormalities and liver and heart complications. ${ }^{18}$ However, patients' compliance with oral therapy is often reported to be poor. $^{17,18,20}$ In non-compliant patients with evidence 
of iron over-load, intravenous deferoxamine is indicated with a good outcome despite the high cost of treatment. ${ }^{17,18}$ In the current case, the patient was placed on intensive intravenous deferoxamine for over a year prior to surgery to correct the iron overload status. Despite the improved iron status, the existence of coagulopathy and diabetes as previous complications of iron over-load were major surgical challenges.

There are a limited number of case reports on the surgical correction of $\beta$-thalassaemia-induced facial deformity. ${ }^{8-10}$ There are few published reports addressing facial deformity in this group which included cases of thalassaemia intermedia., ${ }^{3,9,16}$ The suggested treatment includes surgical reduction of the enlarged maxillary bone and/or surgical jaw correction with or without associated orthodontic treatment. ${ }^{8-10,16}$ Re-contouring the enlarged maxillary bone was a highly suggested treatment option, however, most reports were based on thalassaemia intermedia cases. ${ }^{1,5,8}$ Mortazavi and Khojasteh reported performing surgical re-contouring of the enlarged maxilla with dental clearance of maxillary teeth to facilitate the insertion of dental prosthesis thus, correcting the skeletal and dental deformities. ${ }^{8}$

The most commonly reported surgical form of management of the $\beta$-thalassaemia-induced facial deformity is surgical re-contouring along with either segmental osteotomy or a Le Fort I osteotomy. ${ }^{8-10,16,21,22}$ Segmental osteotomy is more frequently used for vertical and sagittal repositioning of the premaxilla in the inter-canine area after extraction of the bilateral canines or first premolars to produce a reasonable occlusal relationship and facial harmony, ${ }^{8,23}$ Le Fort I osteotomy is less frequently reported in the literature compared to segmental osteotomy and purposely used for superior and posterior repositioning of the enlarged maxilla. ${ }^{8,10,22}$ In earlier reports, there was a preference for carrying out the surgical procedures in two-stages rather than a single-stage, owing to the potential increased risk of bleeding and surgical complications during a single long procedure. ${ }^{8,10,16,21}$ Currently, the tendency is to perform both procedures of recontouring and segmental or Le Fort I osteotomies jointly. ${ }^{8,16}$ In the current case, the decision of surgical treatment was determined based on the patient's choice, haematological status and the potential complications of the treatment. Hence, a singlestage modified Le Fort I osteotomy (large one-unit segmental osteotomy), resection of enlarged maxilla and conventional genioplasty were performed.

The midface is a well-known highly vascularised area and in patients presenting with $\beta$-thalassaemia- induced deformity, this region is further characterised by expansion and very porous cancellous bone, thus, during the surgical procedure, excessive bleeding is expected from mucosal and bone tissues. ${ }^{8,10,22}$ There are no guidelines or consensus for optimal peri-operative $\mathrm{Hb}$ level prior to surgery for $\beta$-thalassaemia major patients, however, transfusion should be considered in patients with low Hb levels. ${ }^{8,10,24}$ Published work has shown that in operated cases of $\beta$-thalassaemiainduced facial deformity between 1969 and 2004, at least 2 units of blood were required as a pre-operative measure $^{8,10}$ Furthermore, blood transfusion was also recommended in the intra- and post-operative stages depending on the nature of bleeding and the $\mathrm{Hb}$ levels. ${ }^{4,8-10,16,22,24}$ Pre-operatively, following an assessment by the haematologist, the current patient's $\mathrm{Hb}$ level was raised to $11.4 \mathrm{~g} / \mathrm{dL}$ and FFP was transfused to correct the coagulopathy status. Intra-operatively, multiple measures were employed to minimise bleeding during the maxillary procedure including hypotensive anaesthesia, sub-periosteal gingival dissection and the application of local measures of oxidised regenerated cellulose packing impregnated with tranexamic acid. In addition, performing a less invasive modified Le Fort I osteotomy instead of the conventional Le Fort I osteotomy, which requires pterygomaxillary disjuncture plates, also contributed in minimising the intra-operative bleeding. Despite all these measures, continuous bleeding from the porous maxilla was encountered intra-operatively and accordingly four units of blood were transfused. Bleeding from the surgical site further reduced following fixation of the maxilla and soft tissue closure. Post-operatively, bleeding from the surgical site and haematoma formation are the most commonly reported complications that need blood transfusion and haematoma evacuation, respectively., ${ }^{8,10}$ The current patient had a drop in $\mathrm{Hb}$ level, which required the transfusion of a further two units of blood. The encountered pre-, intra- and post-operative findings and their management are in line with other published reports..$^{8-10,16}$

The facial surgical correction had a positive impact on the patient's social and psychological status which is in line with the literature. ${ }^{7,8,10,17,22}$ A successful outcome of the dentofacial deformity correction in $\beta$-thalassaemia patients is dependent on understanding the medical status of the patient, coordinating with the haematologist and anaesthesiologist, good surgical planning and preventing complications. ${ }^{8}$ The presented case had a satisfactory and stable outcome in terms of aesthetics and occlusion at 24 months follow-up. 


\section{Conclusion}

Maxillary jaw deformity in $\beta$-thalassaemia major patients is rare and is very challenging surgically. Careful case selection, assessment, pre-operative planning and surgical management are important to avoid complications and to achieve the required surgical outcome.

\section{References}

1. Olivieri NF. The beta-thalassemias. N Engl J Med 1999; 341:99-109. https://doi.org/10.1056/NEJM199907083410207.

2. Cao A, Galanello R. Beta-thalassemia. Genet Med 2010; 12:61-76. https://doi.org/10.1097/GIM.0b013e3181cd68ed.

3. Javid, B, Said-Al-Naief N. Craniofacial manifestations of $\beta$-thalassemia major. Oral Surg Oral Med Oral Patho Oral Radiol 2015; 119:e33-40. https://doi.org/10.1016/j. oooo.2014.08.020

4. Poyton HG, Davey KW. Thalassemia: Changes visible in radiographs used in dentistry. Oral Surg Oral Med Oral Pathol Oral Radiol 1968; 25:564-76. https://doi.org/10.1016/00304220(68)90301-0.

5. Taher A, Isma'eel H, Cappellini MD. Thalassemia intermedia Revisited. Blood Cells Mol Dis 2006; 37:12-20. https://doi. org/10.1016/j.bcmd.2006.04.005.

6. Ficarra G, Hansen LS, Beckstead JH, Stoddard EL, Erickson RT. Thalassemia diagnosed through facial distortion. Int J Oral Maxillofac Surg 1987; 16:227-31. https://doi.org/10.1016/ s0901-5027(87)80136-4.

7. Gharaibeh H, Barqawi MA, Al-Awamreh K, Al Bashtawy M. Clinical burdens of $\beta$-thalassemia major in affected children. J Pediatr Hematol Oncol 2018; 40:182-7. https://doi.org/10.10 97/MPH.0000000000001104

8. Mortazavi SH, Khojasteh A. Superior repositioning of the maxilla in thalassemia-induced facial deformity: Report of 3 cases and a review of the literature. J Oral Maxillofac Surg 2007; 65:1023-31. https://doi.org/10.1016/j.joms.2006.06.305.

9. Park N, Lazow S, Berger J. $\beta$-thalassemia: Medical and surgical considerations in managing facial deformities: Case report and review of the literature. J Oral Maxillofac Surg 2012; 70:e284-9. https://doi.org/10.1016/j.joms.2011.11.027.

10. Drew SJ, Sachs SA. Management of the thalassemia-induced skeletal facial deformity: Case reports and review of the literature. J Oral Maxillofac Surg 1997; 55:1331-9. https://doi. org/10.1016/s0278-2391(97)90197-x.
11. Borgna-Pignatti C, Cappellini MD, De Stefano P, Del Vecchio GC, Forni GL, Gamberini MR. et al. Survival and complications in thalassemia. Ann N Y Acad Sci 2005; 1054:40-7. https://doi. org/10.1196/annals.1345.006.

12. Rachmilewitz EA, Giardina PJ. How I treat thalassemia Blood 2011; 118:3479-88. https://doi.org/10.1182/blood-20 10-08-300335.

13. Cappellini MD, Motta I, Musallam KM, Taher AT. Redefining thalassemia as a hypercoagulable state. Ann N Y Acad Sci 2010; 1202:231-6. https://doi.org/10.1111/j.1749-6632.2010.05548.x.

14. Singh A, Varma S. $\beta$-thalassemia intermedia masquerading as $\beta$-thalassemia major. BMJ Case Rep 2014; 2014:bcr2014207637. https://doi.org/10.1136/bcr-2014-207637.

15. Baker DH. Roentgen manifestations Cooley's anemia. Ann N Y Acad Sci 1964; 119:641-61. https://doi.org/10.1111/j.1749-66 32.1965.tb54064.x.

16. Bouguila J, Besbes G, Khochtali H. Skeletal facial deformity in patients with $\beta$ thalassemia major: Report of one Tunisian case and a review of the literature. Int J Pediatr Otorhinolaryngol 2015; 79:1955-8. https://doi.org/10.1016/j.ijporl.2015.08.037.

17. Rund D, Rachmilewitz E. Beta-thalassemia. N Engl J Med 2005; 353:1135-46. https://doi.org/10.1056/NEJMra050436.

18. Farmaki K, Tzoumari I, Pappa C, Chouliaras G, Berdoukas V. Normalisation of total body iron load with very intensive combined chelation reverses cardiac and endocrine complications of thalassaemia major. Br J Haematol 2010; 148:466-75. https:// doi.org/10.1111/j.1365-2141.2009.07970.x.

19. Musallam KM, Cappellini MD, Daar S, Karimi M, El-Beshlawy A, Graziadei G, et al. Serum ferritin level and morbidity risk in transfusion-independentpatientswith $\beta$-thalassemiaintermedia: The ORIENT study. Haematologica 2014; 99:e218-21. https://doi.org/10.3324/haematol.2013.097220.

20. Farmaki K, Angelopiulos N, Anagnostopoulos G, Gotsis E, Rombopoulos G, Tolis G. Effect of enhanced iron chelation therapy on glucose metabolism in patients with betathalassaemia major. Br J Haematol 2006; 134:438-44. https:// doi.org/10.1111/j.1365-2141.2006.06203.x.

21. Silling G, Moss SJ. Cooley's anemia--orthodontic and surgical treatment. Am J Orthod 1978; 74:444-9. https://doi. org/10.1016/0002-9416(78)90067-2

22. Weel F, Jackson IT, Crookendale WA, McMichan J. A case of thalassaemia major with gross dental and jaw deformities. Br J Oral Maxillofac Surg 1987; 25:348-52. https://doi. org/10.1016/0266-4356(87)90076-3.

23. Naini FB, Gill DS. Orthognathic surgery: Principles, planning and practice. 1st ed. London, UK: John Wiley \& Sons, Inc., 2017.

24. Staikou C, Stavroulakis E, Karmaniolou I. A narrative review of peri-operative management of patients with thalassaemia. Anaesthesia 2014; 69:494-510. https://doi.org/10.1111/anae.12591. 